\title{
ANALISIS KONSERVASI AIR BERBASIS ZERO RUN OFF (STUDI KASUS KAWASAN BLOCK OFFICE BALAI KOTA AMONG TANI KOTA BATU)
}

\author{
Dini Rosvita Tri A. ${ }^{1}$, Mohammad Bisri ${ }^{2}$, Ussy Andawayanti ${ }^{2}$ \\ ${ }^{1}$ Program Magister Teknik, Fakultas Teknik Universitas Brawijaya \\ ${ }^{2}$ Jurusan Pengairan Fakultas Teknik Universitas Brawijaya \\ e-mail : 'dini.rosvita@gmail.com
}

\begin{abstract}
ABSTRAK: Perkembangan Kota Batu sebagai kota wisata dan agropolitan memunculkan beberapa permasalahan terhadap Kota Batu sendiri. Permasalahan sumber daya air yang terjadi adalah penurunan jumlah mata air yang diperkirakan karena alih fungsi hutan menjadi pertanian, serta banyaknya pembangunan permukiman dan tempat wisata. Oleh karenanya perlu dipertahankan kesetimbangan proses pengambilan dan pengisian air hujan dengan meresapkan ke dalam pori-pori tanah atau batuan melalui konservasi air. Dari hasil penelitian ini diharapkan diperoleh model konservasi air berbasis zero run off yang dapat diterapkan di lokasi studi, selanjutnya dapat menjadi masukan bagi Pemerintah setempat dan dikembangkan di Kota Batu. Penelitian ini mengkaji analisis konservasi air berbasis konsep zero run off dengan lokasi studi Block Office Among Tani. Analisis limpasan permukaan dihitung menggunakan Metode Rasional. Dimensi sumur resapan dihitung menggunakan metode SNI 032453 2002. Dari hasil analisis diperoleh besarnya debit rancangan dengan kala ulang 5 tahun adalah 111,408 mm. Untuk memenuhi konsep zero run off direncanakan sumur resapan dengan ketinggian 5 meter dan diameter 1 meter. Jumlah sumur resapan untuk luasan atap $100 \mathrm{~m}^{2}$ adalah 1 buah. Dengan penerapan teknologi konservasi air berupa sumur resapan, mampu menampung limpasan atap, kolam retensi dapat menampung dan meresapkan limpasan dari area parkir, jalan, dan pekarangan.
\end{abstract}

Kata kunci: zero run off, limpasan keruangan, konservasi air, sumur resapan.

\begin{abstract}
The development of Batu as a tourist and agropolitant city has led to some concern, such as water resources. The number of springs has increasingly declined due to the conversion of forest into agriculture land, residential, and tourist sites. Therefore, it's necessary to maintain equilibrium through the process of extracting and replenishment of rain water by absorbing it into soil pores as water conservation efforts. This study examines the analysis of water conservation based on the concept of zero runoff, located in the Block Office area. It is expected to become input for the Batu City Government and be developed in those area. The analysis of surface runoff is calculated by Rational Method. The dimension of recharged well is calculated by using SNI method 032453 2002. The magnitude of design discharge obtained with 5 years return period is 111,408 mm. Reharged well is planned with 5 meters height and 1 meter diameter. Recharged well used for $100 \mathrm{~m}^{2}$ roof area is 1 . Water conservation technology by using recharged well is able to collect runoff from the roof, while retention pool collect and absorb runoff from the parking area, road, and yard.
\end{abstract}

Keywords: zero run off, spatial run off, water conservasion, recharged well

Peningkatan sektor perekonomian dan jumlah penduduk yang pesat menuntut adanya pembangunan sarana fisik, perumahan, penyediaan air baku, sanitasi, sarana kesehatan, dan beberapa fasilitas lainnya. Laju pembangunan yang terus meningkat semakin mengurangi lahan terbuka. Alih fungsi lahan tersebut dapat menyebabkan terjadinya 
genangan di musim hujan, menurunnya debit air di musim kemarau, bahkan dapat menyebabkan perubahan sifat biofisik suatu Daerah Aliran Sungai (DAS) (Sucipto, 2008).

Kota Batu yang berkembang menjadi kota wisata dan agropolitan telah memunculkan beberapa permasalahan terhadap Kota Batu. Data dari Dinas Lingkungan Hidup Kota Batu, dulu terdapat 111 mata air tinggal 81 sumber saja. Sementara itu, 30 sumber lainnya mempunyai debit yang sangat kecil. Arief (2017) menyatakan bahwa penurunan jumlah mata air di Kota Batu diperkirakan karena adanya alih fungsi lahan hutan menjadi pertanian, selain disebabkan pula oleh banyaknya pembangunan, baik permukiman maupun tempat wisata. Dari hasil penelitian oleh Permanasari, Bisri, dan Suharyanto, (2012) menunjukkan penggunaan lahan di Kota Batu pada tahun 2010 mempunyai pengaruh pada penurunan daya resap air hujan ke dalam tanah, yakni menurun $34.915 .235 \mathrm{~m}^{3} /$ tahun atau $13 \%$ dari penggunaan lahan di tahun 2003.

Seiring dengan hal tersebut di atas telah terbit aturan terbaru yang mengimplementasikan sistem drainase berwawasan lingkungan berbasis konservasi, yang tertuang dalam dua Peraturan Menteri Pekerjaan Umum yaitu nomor 12/PRT/M/2014 tentang penyelenggaraan sistem drainase perkotaan (mengharuskan perencanaan drainase perkotaan yang berbasis ramah lingkungan) yang mempertegas peraturan nomor 11/PRT/M/2014 tentang pemanfaatan (pengelolaan) air hujan untuk gedung dan pekarangannya (persilnya).

Berdasarkan peraturan tersebut, maka perlu dipertahankan kesetimbangan proses pengambilan dan pengisian air hujan (presipitasi dan infiltrasi) dengan meresapkan ke dalam pori-pori/rongga tanah, serta dilakukan upaya konservasi air. Prinsip dasar konservasi air adalah mencegah atau meminimalkan air yang hilang sebagai aliran permukaan dan menyimpannya semaksimal mungkin ke dalam tubuh bumi.

Di samping itu, terbit juga Peraturan Pemerintah Nomor 26 Tahun 2008 tentang Rencana Tata Ruang Wilayah menyebutkan Konsep zero delta $Q$ policy (ZDQP). Konsep ini adalah sebuah konsep yang menyebutkan keharusan agar tiap bangunan tidak boleh mengakibatkan bertambahnya debit air ke sistem saluran drainase atau sistem aliran sungai. Artinya setiap bangunan gedung atau kawasan harus mengelola air limpasan (run off) di dalam persil atau kawasannya sendiri. Hal ini dimaksudkan agar debit limpasan yang mengalir ke luar persil atau ke luar kawasan selalu menyamai atau lebih baik dari kondisi naturalnya.

Berdasarkan hasil penelitian Bisri \& Titah (2009) bahwa penerapan sumur resapan merupakan salah satu solusi tercepat untuk konservasi air tanah dan yang paling memungkinkan untuk dilaksanakan di kota Batu, mengingat kondisi muka air tanah yang terus menurun dari tahun ke tahun.

Tujuan dilaksanakannya penelitian ini adalah melakukan analisis konservasi air berbasis zero run off yang dapat diterapkan di berdasarkan debit limpasan menggunakan hujan rancangan kala ulang 5 tahunan.

\section{BAHAN DAN METODE Kondisi Daerah Studi}

Studi ini dilakukan di kawasan Block Office Balai Kota Among Tani Kota. Secara administratif kawasan ini terletak di Kecamatan Batu Kota Batu. Gambaran Lokasi Studi seperti pada Gambar 1.

Dasar pemilihan lokasi ini adalah bahwa kawasan ini merupakan kawasan strategis, disamping mempunyai potensi pengembangan pembangunan wilayah kota yang cukup baik. Dengan terbangunnya kawasan ini, lahan terbuka dan resapan air semakin berkurang.

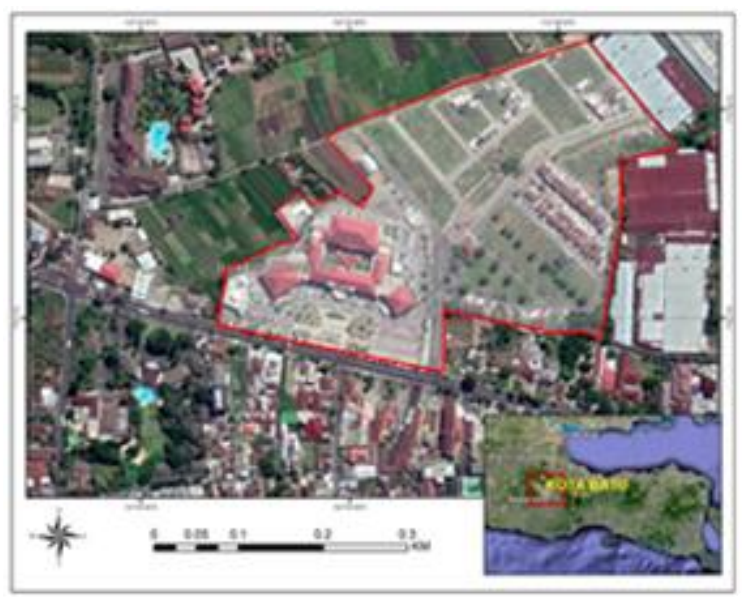

Gambar 1. Lokasi Studi

Sumber: Google Earth dan Hasil Pengolahan, 2019

Pengumpulan Data

Data yang dipergunakan untuk penelitan ini adalah sebagai berikut

1. Data curah hujan stasiun penakar hujan Ngaglik bersumber dari Dinas Pekerjaan Umum. Adapun data yang digunakan 
adalah data tahun 2008 - 2017.

2. Peta topografi (kontur) untuk mengetahui kondisi alam, elevasi, dan arah aliran serta sebagai peta dasar, bersumber dari Dinas Perumahan, Kawasan Permukiman dan Pertanahan Kota Batu, ditambahkan survey lapangan.

3. Gambar master plan dan lay out lokasi studi, serta peta jaringan drainase eksisting bersumber dari Dinas Perumahan, Kawasan Permukiman dan Pertanahan Kota Batu dan pengembang perumahan,

4. Data jumlah penduduk

5. Data muka air tanah dari hasil pengamatan sumur pantau lokasi studi,

6. Peraturan Standar Nasional Indonesia (SNI) 0324532002 tentang Tata Cara Perencanaan Teknik Sumur Resapan Air Hujan Untuk Lahan Pekarangan.

\section{Uji Konsistensi Data Hujan}

Untuk menguji konsistensi data hujan pada stasiun individual (stand alone station) digunakan metode Rescaled Adjusted Partial Sums (RAPS). Cara RAPS membandingkan hasil uji statistik dengan $Q_{R A P S} / \sqrt{n}$. Bila yang didapat lebih kecil dari nilai kritis untuk tahun dan confidence level yang sesuai, maka data dinyatakan konsisten.

\section{Sumur Resapan}

Volume dan efisiensi sumur resapan dapat dihitung berdasarkan keseimbangan air yang masuk ke sumur dan air yang meresap ke dalam tanah (Sunjoto dalam Kementerian Pekerjaan Umum, 2013).

Debit air dalam sumur yang meresap, digunakan rumus:

$H=\frac{Q}{F \cdot K}\left[1-e^{\left[\frac{F \cdot K . T}{\pi \cdot R^{2}}\right]}\right]$

$$
\begin{aligned}
& \text { Keterangan : } \\
& \mathrm{H}=\text { tinggi muka air dalam sumur }(\mathrm{m}) \\
& \mathrm{F}=\text { faktor geometrik }(\mathrm{m}) \\
& \mathrm{Q}=\text { debit air masuk }\left(\mathrm{m}^{3} / \text { detik }\right) \\
& \mathrm{T}=\text { waktu/ durasi pengaliran }(\mathrm{detik}) \\
& \mathrm{K}=\text { koefisien permeabilitas tanah }(\mathrm{m} / \mathrm{dt}) \\
& \mathrm{R}=\text { jari }- \text { jari/ radius sumur }(\mathrm{m})
\end{aligned}
$$

\section{HASIL DAN PEMBAHASAN \\ Uji Konsistensi Data Hujan}

Karena data hujan yang digunakan dalam penelitian berasala dari satu stasiun pengukur hujan, maka digunakan metode
Rescaled Adjusted Partial Sums (RAPS), dengan perhitungan sebagaimana ditampilkan pada Tabel 1.

$\mathrm{n}=10$

Simp. Rata-rata, $\mathrm{D}_{=}=18,47$

$\mathrm{Sk}^{* *} \mathrm{mak}=1,916$

$\mathrm{Sk}^{* *} \min =-1,061$

$\mathrm{Q}=|\mathrm{Sk} * * \operatorname{mak}|=1,916$

$\mathrm{R}=\mathrm{Sk} * * \mathrm{mak}-\mathrm{Sk}{ }^{* *} \mathrm{~min}=2,977$

Tabel 1. Uji Konsitensi Data Hujan

\begin{tabular}{|r|r|r|r|r|r|r|}
\hline No & $\begin{array}{c}\text { Tahu } \\
\mathrm{n}\end{array}$ & $\begin{array}{c}\text { Hujan } \\
(\mathrm{mm} / \mathrm{hari} \\
)\end{array}$ & \multicolumn{1}{c|}{$\mathrm{Sk}^{*}$} & \multicolumn{1}{c|}{$\mathrm{D}_{\mathrm{y}}{ }^{2}$} & $\mathrm{Sk}^{* *}$ & $\begin{array}{c}{\left[\mathrm{Sk}^{* *}\right.} \\
]\end{array}$ \\
\hline \hline 1 & 2008 & 74,00 & $-0,60$ & 0,04 & $-0,03$ & 0,03 \\
2 & 2009 & 86,00 & 11,40 & 13,00 & 0,62 & 0,62 \\
3 & 2010 & 103,00 & 28,40 & 80,66 & 1,54 & 1,54 \\
4 & 2011 & 63,00 & $-11,60$ & 13,46 & $-0,63$ & 0,63 \\
5 & 2012 & 58,00 & $-16,60$ & 27,56 & $-0,90$ & 0,90 \\
6 & 2013 & 110,00 & 35,40 & 125,32 & 1,92 & 1,92 \\
7 & 2014 & 68,00 & $-6,60$ & 4,36 & $-0,36$ & 0,36 \\
8 & 2015 & 74,00 & $-0,60$ & 0,04 & $-0,03$ & 0,03 \\
9 & 2016 & 55,00 & $-19,60$ & 38,42 & $-1,06$ & 1,06 \\
10 & 2017 & 55,00 & $-19,60$ & 38,42 & $-1,06$ & 1,06 \\
\hline
\end{tabular}

Sumber: Hasil Analisis, 2019

Dari hasil perhitungan diperoleh nilai $Q / n^{0.5}$ adalah 0,607 dan $R / n^{0.5}$ adalah 0,942 kemudian dibandingkan dengan nilai kritis pada $n=10$. Diperoleh nilai $Q / n^{0.5}$ hitung dan $R / n^{0.5}{ }_{\text {hitung }}<Q / n^{0.5}$ tabel dan $R / n^{0.5}$ tabel. Hasil tersebut menunjukkan bahwa data hujan pada stasiun pencatat hujan Ngaglik adalah konsisten.

\section{Analisa Frekuensi}

Tabel 2. Curah Hujan Rancangan

\begin{tabular}{|c|c|c|c|c|l|}
\hline $\mathrm{T}$ & $\mathrm{P}(\%)$ & $\mathrm{Cs}$ & $\mathrm{G}$ & $\log \mathrm{X}$ & $\mathrm{X}(\mathrm{mm})$ \\
\hline 2 & 50 & 0,588 & 0,801 & 1,947 & 88,425 \\
5 & 20 & 0,588 & 1,733 & 2,047 & 111,408 \\
10 & 10 & 0,588 & 1,935 & 2,069 & 117,150 \\
20 & 5 & 0,588 & 2,353 & 2,114 & 129,933 \\
25 & 4 & 0,588 & 2,746 & 2,156 & 143,247 \\
50 & 2 & 0,588 & 3,121 & 2,196 & 157,178 \\
100 & 1 & 0,588 & 3,942 & 2,285 & 192,682 \\
\hline
\end{tabular}

Sumber: Hasil Analisis, 2019

Analisa frekuensi data intensitas hujan kala ulang 5 tahun dilakukan dengan menggunakan distribusi Log Pearson Tipe III. Tabel 2 
menunjukkan hasil analisa curah hujan rancangan dengan menggunakan metode Log Pearson Tipe III.

Dari tabel tersebut, untuk analisis selanjutnya pada penelitian ini digunakan nilai hujan rancangan hasil analisis dengan kala ulang 5 tahunan yaitu $111,408 \mathrm{~mm}$.

\section{Analisis Konservasi Air Hujan Dengan Sumur Resapan dan Kolam Retensi}

\section{1) Analisis Konservasi Air Pada Perumahan}

Dalam pembangunan sumur resapan, air yang dimasukkan dalam sumur resapan adalah air hujan. Dengan demikian, luas area tadah yang dimaksud adalah luas atap rumah. Adapun luas atap rumah di perumahan bervariasi sesuai tipe dan desain rumah.

Pada contoh perhitungan ini diambil nilai $\mathrm{A}_{\text {Tadah }}=100 \mathrm{~m}^{2}$, dengan $C_{\text {atap }}$ adalah 0,90 . Dengan hujan rencana kala ulang 5 tahun sebesar 111,408 mm/jam.

1. Faktor geometri sumur, $\mathrm{F}$

$$
\begin{gathered}
F=\frac{2 \pi L+2 \pi R \operatorname{Ln}(2)}{\operatorname{Ln}\left[\frac{L+2 R}{2 R}\right]+\sqrt{1+\left[\frac{L}{2 R}\right]^{2}}} \\
F=\frac{(2 \pi \times 2)+(2 \pi \times 0,50 \times \operatorname{Ln}(2))}{\operatorname{Ln}\left[\frac{2+2(0,50)}{2 \times 0,50}\right]+\sqrt{1+\left[\frac{2}{2 \times 0,5}\right]^{2}}} \\
=8,909
\end{gathered}
$$

2. Menghitung debit limpasan atap $\left(\mathrm{Q}_{\text {atap }}\right)$

$$
\begin{aligned}
Q & =C I A \\
& =0,90 \times 0,0472 \times 100 \\
& =4,248 \mathrm{~m}^{3} / \mathrm{jam}=0,00118 \mathrm{~m}^{3} / \text { detik }
\end{aligned}
$$

3. Menghitung kedalaman sumur rencana dengan $Q_{\text {atap }}=4,248 \mathrm{~m}^{3} / \mathrm{jam}$

$$
\begin{aligned}
H & =\frac{Q}{F K}\left\{1-e\left(\frac{-F K T}{\pi R^{2}}\right)\right\} \\
& =\frac{4,248}{8,909 \times 0,02}\left\{1-e\left(\frac{-8,909 \times 0,02}{\pi R(0,6)^{2}}\right)\right\} \\
& =5,49 \mathrm{~m}
\end{aligned}
$$

4. Menghitung kemampuan sumur resapan untuk 1 atap rumah

Direncanakan sumur resapan dengan kedalaman 5 meter, maka:

$$
\begin{aligned}
n & =\frac{H_{\text {analisa }}}{H_{\text {rencana }}} \\
& =\frac{5,49}{5}
\end{aligned}
$$

$=1,08 \simeq 1$ buah

Artinya adalah tiap satu rumah dengan luasan atap $100 \mathrm{~m}^{2}$, membutuhkan 1 (satu) sumur resapan dengan kedalaman 6 meter dan diameter 0,50 meter, berlaku bila terjadi hujan dengan intensitas, $I=47,20 \mathrm{~mm} / \mathrm{jam}$ dengan waktu hujan efektif, $T e=1,146 \mathrm{jam}$.
Dengan cara yang sama, dihitung jumlah kebutuhan sumur resapan di perumahan.jumlah total sumur resapan adalah 135 buah untuk ditempatkan di lokasi perumahan Batu Panorama. Adapun dimensi dan tipikal sumur resapan sebagai bangunan konservasi air di Perumahan Batu Panorama dapat dilihat pada Gambar 4. Penempatan sumur resapan di tiap rumah seperti pada Gambar 5.

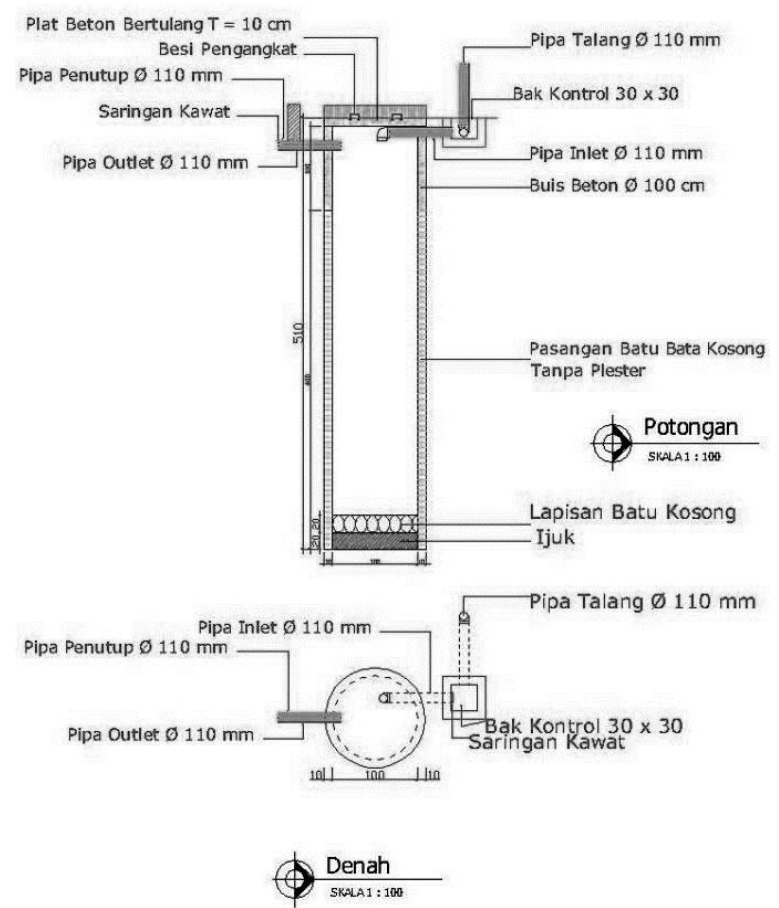

Gambar 4. Tipical Sumur Resapan

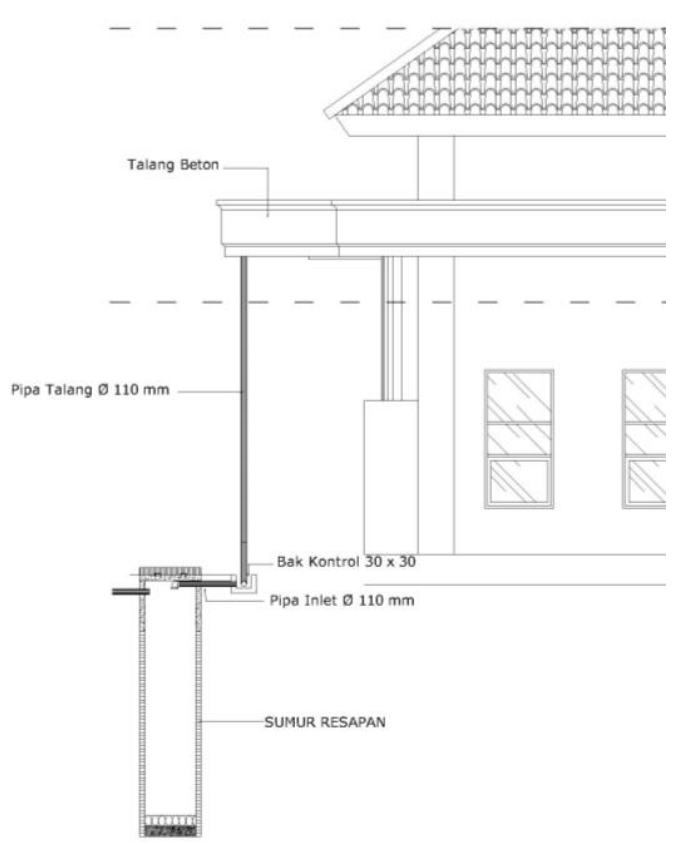

Gambar 5. Penempatan Sumur Resapan tampak samping 
Untuk debit limpasan selain dari atap, direncanakan kolam retensi yang letaknya pada saluran utama pada drainase internal perumahan. Berdasarkan hasil analisis debit menggunakan rumus rasional, diperoleh besarnya debit limpasan yang terjadi selain pada atap adalah sebesar $0,1418 \mathrm{~m}^{3} /$ detik.

Agar terpenuhi konsep zero run off di perumahan, maka direncanakan kolam retensi untuk debit limpasan non atap dengan kala ulang 5 tahunan sebesar $0,1418 \mathrm{~m}^{3} / \mathrm{dt}$ dengan dimensi $15 \times 20 \times 2$ meter

\section{2) Analisis Konservasi Air Pada Block Office}

Untuk mengetahui besarnya debit limpasan yang dapat dimanfaatkan untuk konservasi air, terlebih dahulu dihitung volume hujan atap tiap gedung dengan langkah seperti pada bagian sebelumnya. Hasil perhitungan dapat dilihat pada Tabel 3 dan hasil perhitungan jumlah sumur resapan yang dapat dibangun di tiap gedung adalah sebagaimana dirinci pada Tabel 4.

Tabel 3. Perhitungan Volume Limpasan Atap

\begin{tabular}{|l|l|c|}
\hline No. & Nama Gedung & $\begin{array}{c}\text { V limp. atap } \\
\left(\mathbf{( m}^{\mathbf{3}} \mathbf{)}\right.\end{array}$ \\
\hline 1. & Gedung A & 86,29 \\
\hline 2. & Gedung B & 98,32 \\
\hline 3. & Gedung C & 51,07 \\
\hline 4. & Graha pancasila & 35,87 \\
\hline 5. & Masjid & 11,26 \\
\hline
\end{tabular}

Sumber: Hasil Analisa, 2019

Tabel 4. Perhitungan Jumlah Sumur Tiap Gedung

\begin{tabular}{|c|c|c|c|}
\hline No. & Sub DTA & $\begin{array}{c}\text { Luas } \\
\text { Tadah } \\
\left(\mathbf{m}^{2}\right)\end{array}$ & $\begin{array}{c}\text { Jumlah } \\
\text { Sumur }\end{array}$ \\
\hline 1 & Gedung A & 840 & 5 \\
\hline 2 & Gedung B & 2800 & 17 \\
\hline 3 & Gedung C & 2880 & 17 \\
\hline 4 & Graha Pancasila & 1740 & 10 \\
\hline
\end{tabular}

Sumber: Hasil Analisa, 2019

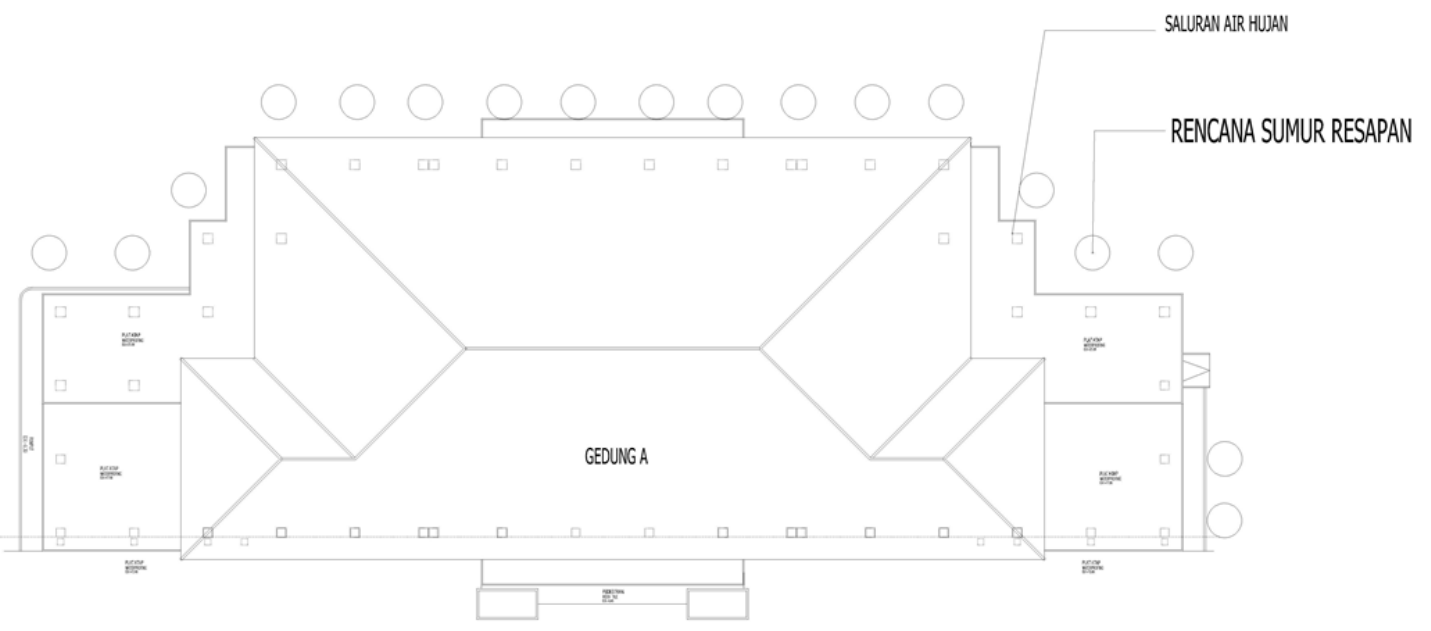

Gambar 6. Penempatan Sumur Resapan

Sumber: Hasil Analisis

Limpasan yang terjadi pada lahan non atap akan dialirkan melalui drainase internal, dan dimasukkan ke dalam kolam retensi yang dibangun di bawah area parkir.

Luas Paving $=22.479,90$

$C_{\text {paving }}=0,7$

Dengan rumus rasional, dihitung $Q_{\text {limpasan }}=$ $0,158 \mathrm{~m}^{3} / \mathrm{dtk}$

Untuk debit limpasan non atap dengan kala ulang 5 tahunan sebesar $0,158 \mathrm{~m}^{3} / \mathrm{dt}$ dengan durasi hujan efektif 1,146 jam:

$\mathrm{V}=0,158 \times 60 \times 60 \times 1,146$

$$
=650,215 \mathrm{~m}^{3}
$$

Diperoleh dimensi kolam retensi untuk di block office adalah 10x10x 4 meter sebanyak 2 (dua) buah

\section{KESIMPULAN}

Mengingat adanya keterbatasan ruang di lokasi yang terbangun, serta memperhatikan persyaratan teknis pembangunan sarana konservasi air, maka bangunan konservasi air yang direkomendasikan adalah type resapan berupa sumur resapan dan kolam retensi.

a. Bangunan konservasi air di block office 
Sumur resapan digunakan untuk limpasan hujan atap diameter 1 meter dan kedalaman 5 meter dengan jumlah total 53 buah. Sementara itu untuk limpasan non atap digunakan kolam retensi sebanyak 2 buah. Dimensi kolam retensi adalah panjang 10 meter, lebar 10 meter dan kedalaman 4 meter.

b. Bangunan konservasi air di perumahan Batu Panorama

Sumur resapan digunakan untuk limpasan hujan atap, sumur yang digunakan mempunyai diameter 1 meter dan kedalaman 5 meter dengan jumlah total 135 buah. Adapun lokasi pembangunan sumur terlampir. Sementara itu untuk limpasan non atap digunakan kolam retensi dengan dimensi panjang 15 meter, lebar 20 meter dan kedalaman 2 meter.

\section{UCAPAN TERIMA KASIH :}

Ucapan terima kasih kami sampaikan sebesar-besarnya kepada Kementerian Pekerjaan Umum dan Perumahan Rakyat melalui Badan Pengembangan Sumber Daya Manusia yang telah memberikan beasiswa pendidikan kedinasan pada Program Magister Teknik Pengairan Universitas Brawijaya Malang. Serta kepada pihak-pihak yang membantu pengumpulan data primer maupun sekunder (Laboratorium Air dan Tanah Teknik Pengairan, Dinas Lingkungan Hidup Kota Batu, Dinas PU dan Penataan Ruang Kota Batu) yang digunakan untuk penelitian ini. Juga kepada rekan-rekan karyasiswa PU Magister Teknik Pengairan angkatan 2017.

\section{DAFTAR PUSTAKA}

Arief. (2017). Awas, Mata Air di Kota Batu Mulai Terkuras; Wajibkan Bangunan

Baru Membuat Sumur Resapan. Jawa Pos. 11 Desember. Hlm. 5.

Badan Standarisasi Nasional. (2002). SNI: 032453-2002. Tata Cara Perencanaan Sumur Resapan Air Hujan untuk Lahan Pekarangan. Jakarta: Badan Standarisasi Nasional.

Bisri, M., dan Prastya, T.A.N. (2009). Imbuhan Air Tanah Buatan Untuk Mereduksi Genangan (Studi Kasus di Kecamatan Batu Kota Batu).Jurnal. Malang.

Departemen Permukiman dan Prasarana Wilayah. (2000). Tata Cara Perencanaan Teknik Sumur Resapan Air Hujan Untuk Lahan Perkarangan. Bandung: Kementerian Pekerjaan Umum.

Permanasari,Puspa.,Bisri, M., \& Suharyanto, A. (2012). Pengaruh Guna Lahan Terhadap Penurunan Infiltrasi di Kota Batu. Jurnal. Malang

Soemarto, CD. (1995). Hidrologi Teknik. Jakarta: Airlangga

Sucipto. (2008). Teori dan Praktek Ekologi. Surabaya: Airlangga Universitas Press

Sunjoto. (2011). Teknik Drainase Pro-Air. Yogyakarta: Universitas Gajah Mada

Walikota Batu. (2015). Peraturan Walikota Batu Nomor 21 Tahun 2015 tentang Pembuatan Sumur Resapan dan Biopori. Batu: Walikota Batu. 